\title{
Research nurses as practice facilitators to disseminate an asthma shared decision making intervention
}

Lindsay Shade ${ }^{1 *}$, Kelly Reeves ${ }^{1}$, Jennifer Rees ${ }^{2}$, Lori Hendrickson ${ }^{3}$, Jacqueline Halladay ${ }^{4}$, Rowena J. Dolor ${ }^{5}$, Paul Bray ${ }^{6}$ and Hazel Tapp ${ }^{1}$

\begin{abstract}
Background: Practice facilitation is a method of introducing and sustaining organizational change. It involves the use of skilled healthcare professionals called practice facilitators (PFs) to help address the challenges associated with implementing evidence-based guidelines and complex interventions into practice. PFs provide a framework for translating research into practice by building relationships, improving communication, fostering change, and sharing resources. Nurses are well positioned to serve as PFs for the implementation of complex interventions, however, there is little evidence currently available to describe nurses in this role. Additionally, the best strategies to implement complex interventions into practices are still not fully understood. Combining practice facilitation with the train-the-trainer model has the potential to spread knowledge and skills. Shared decision making (SDM), which involves patients and providers jointly engaging in decisions around treatment options, has been shown to improve outcomes for patients with asthma. The goal of this manuscript is to describe and evaluate the practice facilitation process from the ADAPT-NC Study which successfully utilized research nurses to implement a complex asthma SDM toolkit intervention into primary care practices.

Methods: As part of a larger study, 10 primary care practices were recruited for a facilitator-led dissemination intervention involving a 12-week rollout of an asthma SDM toolkit (trial registration: 1.28.2014, \#NCT02047929). An experienced lead PF trained research nurses as PFs from each of the 4 participating practice-based research networks (PBRNs) in a train-the-trainer model utilizing a one-day training event and subsequent remote meetings. Evaluation of PF engagement was measured through process improvement surveys.

Results: Overall, the asthma SDM intervention was successfully implemented within the 4 PBRNs. All 10 facilitatorled practices remained engaged with their PFs, with 8 out of the 10 practices able to incorporate and sustain SDM visits or clinics. Responses from the surveys for process improvement yielded improved PF communication and team dynamics over time.

(Continued on next page)
\end{abstract}

\footnotetext{
* Correspondence: lindsay.shade@atriumhealth.org

${ }^{1}$ Atrium Health, Department of Family Medicine Research, 2001 Vail Avenue,

Suite 400B Mercy Medical Plaza, Charlotte, NC 28207, USA

Full list of author information is available at the end of the article
}

(c) The Author(s). 2020 Open Access This article is licensed under a Creative Commons Attribution 4.0 International License, which permits use, sharing, adaptation, distribution and reproduction in any medium or format, as long as you give appropriate credit to the original author(s) and the source, provide a link to the Creative Commons licence, and indicate if changes were made. The images or other third party material in this article are included in the article's Creative Commons licence, unless indicated otherwise in a credit line to the material. If material is not included in the article's Creative Commons licence and your intended use is not permitted by statutory regulation or exceeds the permitted use, you will need to obtain permission directly from the copyright holder. To view a copy of this licence, visit http://creativecommons.org/licenses/by/4.0/ The Creative Commons Public Domain Dedication waiver (http://creativecommons.org/publicdomain/zero/1.0/) applies to the data made available in this article, unless otherwise stated in a credit line to the data. 
(Continued from previous page)

Conclusions: This study demonstrated effective use of research nurses as practice facilitators during the dissemination of an asthma SDM intervention into primary care practices, adding to the knowledge of best practices by describing a model of large-scale implementation of a complex intervention through practice facilitation with nurses.

Trial registration: "Comparing Traditional and Participatory Dissemination of a Shared Decision Making Intervention" was retrospectively registered at https://clinicaltrials.gov/ on January 28th, 2014 (NCT02047929).

Keywords: Practice facilitation, Dissemination, Implementation, Asthma, Shared decision making, Intervention, Nurse

\section{Background}

Practice facilitation is a method of introducing and sustaining organizational change [1]. It involves the use of skilled healthcare professionals called practice facilitators (PFs) to help address the challenges associated with implementing evidence-based guidelines and complex interventions into practice [2]. PFs are individuals who work to achieve continuous quality improvement through a series of incremental plan-do-study-act cycles [1]. These PFs provide a framework for translating research into practice by building relationships, improving communication, fostering change, and sharing resources [3]. Throughout the literature, practice facilitation has been shown to improve evidence-based guideline adoption, preventive care, smoking cessation, chronic illness care including diabetes, and cancer care [2, 4-11].

Nurses are well positioned to serve as PFs for the implementation of complex interventions. During their training, nurses build skills around being detailed and organized, patient and resilient, and learn how to think critically to make quick decisions [12]. These attributes are essential for practice facilitation, however, there is little evidence currently available to describe nurses in this role.

Additionally, the best strategies to implement complex interventions into practices are still not fully understood. In healthcare, the train-the trainer model leverages the experience of one provider or clinician to train others, who in turn disseminate the information onto others in their workplaces or communities [13-16]. Combining practice facilitation with the train-the-trainer model has the potential to spread knowledge and skills to a greater extent. Utilizing research nurses as PFs in a train-thetrainer approach, we disseminated a complex intervention for asthma across the state of North Carolina.

Asthma is a complex and costly chronic lung disease that affects 1 in 13 Americans [17]. Over 24 million children and adults are living with asthma in the United States, annually accumulating 10.5 million office visits, 1.8 million emergency department (ED) visits, and 440,000 hospitalizations [18]. The burden of this health care utilization amounts to $\$ 56$ billion per year in medical expenses, loss of productivity, and premature death [19]. Unfortunately, 10 Americans die every day from complications of their asthma [18]. Interventions are needed to improve patient outcomes given the high prevalence, morbidity, and mortality associated with asthma.

Improving provider adherence to guideline recommendations may help improve outcomes for patients with asthma [20, 21]. Providers often underutilize the National Hearts, Lung, and Blood Institute's guidelines for managing asthma and adherence is thought to be poor in part because of guideline length and complexity [2123]. The guideline's stepwise approach for managing asthma involves medication selection in varying doses and combinations dependent upon the patient's age, severity classification, and control level [22]. It can be challenging for busy providers to quickly process this multitude of information when making medication selections with an asthma patient. Interventions, such as shared decision making (SDM) that improve patient/ provider communication and simplify the medication selection process may help improve guideline adherence and patients' outcomes.

SDM is an approach to care delivery that involves patients and providers jointly engaging in decisions around treatment options [24]. In SDM, both the patient and provider share relevant information, thus partner in their health care decisions. For the patient, this may include their personal values and lifestyle choices; for the provider, this may include pertinent disease information and the benefits and risks of various medications. The patient and provider together express their preferences with regards to treatments, such as improving disease control, minimizing side effects, limiting costs, or prioritizing convenience of the regimen. The patient and provider then discuss several evidence-based options and work towards an agreement on a treatment regimen [25, 26]. This SDM process has been shown to improve medication adherence and clinically relevant disease outcomes for patients with asthma [26-29].

North Carolina (NC) is home to over 635,000 patients with asthma, affecting $8.4 \%$ of its residents [30]. The Mecklenburg Area Partnership for Primary Care Research 
(MAPPR), a practice-based research network (PBRN) based in Charlotte, NC, previously developed and implemented an asthma SDM toolkit intervention at 6 underserved practices through practice facilitation $[24,27,28$, 31-34]. The intervention involved a team approach utilizing a health coach and toolkit comprised of decision aids, including evidence-based treatment options to streamline the medication selection process and improve asthma control (Fig. 1). To incorporate SDM for asthma care into the practices, the toolkit intervention focused on 5 essential components of SDM: (1) establishing the patient's perception of current asthma control; (2) addressing medication adherence; (3) providing asthma education including "what is asthma," controller versus rescue medications, correct inhaler technique, and trigger avoidance; (4) establishing treatment goals and medication preferences; (5) and finally negotiating several evidence-based treatment options based on the patient's actual severity or control level. Using elements of the chronic care model and community-placed research, the complex toolkit intervention was tailored to fit the needs of each practice individually over a 12 -week rollout period [27, 31, 35, 36]. Results from this pragmatic pilot study showed significantly reduced exacerbation rates in pediatric patients with asthma [27].

From 2013 to 2016, the ADAPT-NC (Asthma Dissemination Around Patient-centered Treatments in North Carolina) Study evaluated dissemination methods of the asthma SDM toolkit intervention through a large comparative effectiveness study, building on the work from our previous pilot [24, 27-29, 31-34, 37-42]. Research nurses were trained as PFs to disseminate the intervention. Results of the ADAPT-NC Study showed a significantly higher portion of asthma patients shared equally in the decision-making with their provider in the facilitator-led dissemination arm (75\%; 95\% CI [71.7, 78.1]) compared to a traditional lunch-and-learn approach $(66 \%$; 95\% CI $[62.8,69.8])(p=0.001)$ [29]. The facilitator-led arm also had the lowest proportion of patients visiting the ED (14\% decrease for facilitator-led (95\% CI $[+4 \%,-32 \%], p=0.21), 12 \%$ decrease for traditional lunch-and-learn (95\% CI [+11\%, - 35\%], $p=$

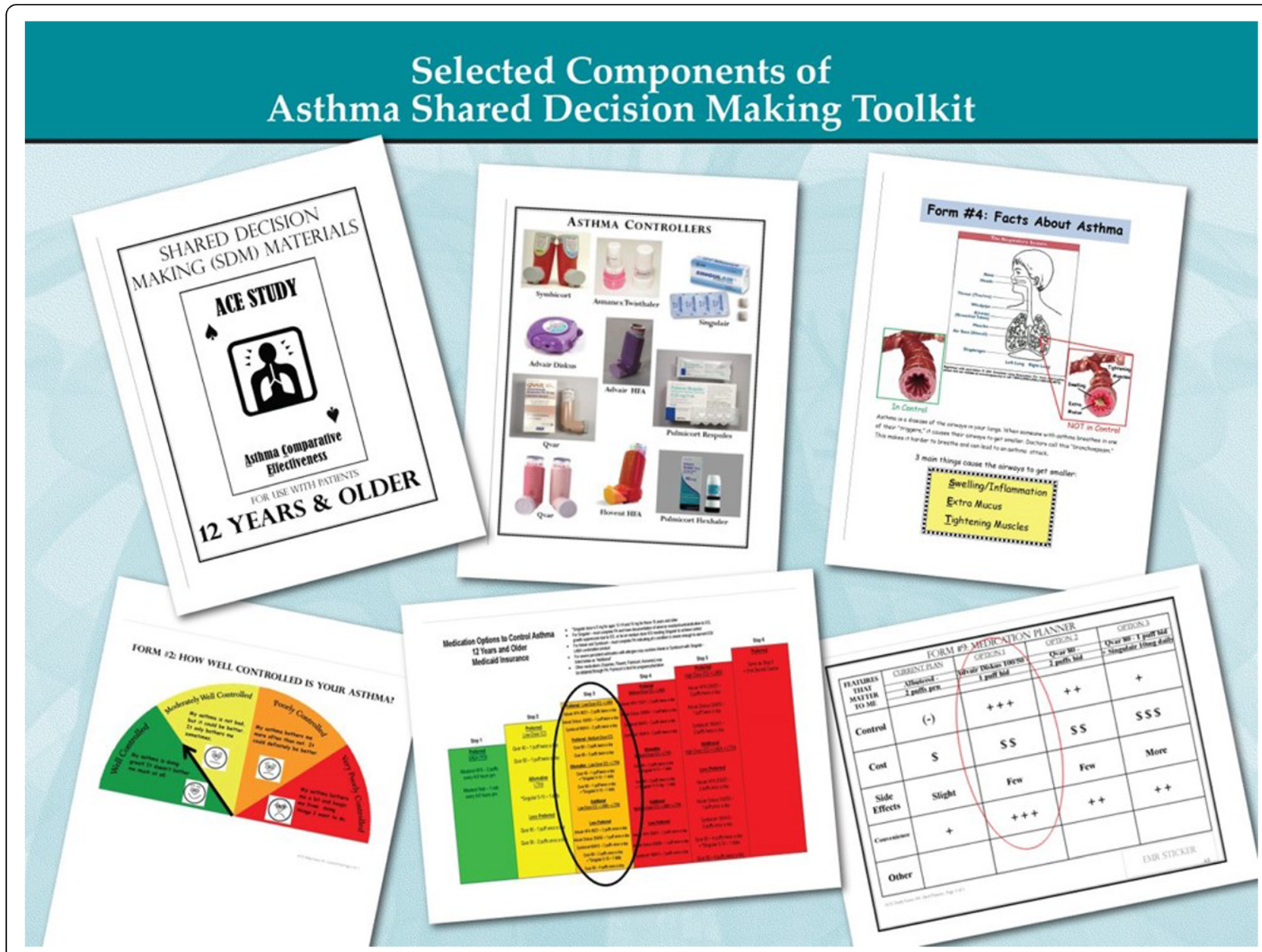

Fig. 1 Selected Components of Asthma Shared Decision Making Toolkit. The images depicted in Fig. 1 are our own 
0.09 ), and $9 \%$ increase for usual care $(95 \%$ CI $[+28 \%$, $10 \%$ ], $p=0.28)$ ) [29]. These results suggest that complex interventions such as SDM are most effectively implemented in practices using a structured, facilitator-led approach.

The goal of this manuscript is to describe and evaluate the practice facilitation process from the ADAPT-NC Study which successfully utilized research nurses to implement a complex asthma SDM toolkit intervention into primary care practices.

\section{Methods}

\section{Setting}

The ADAPT-NC Study leveraged the partnerships of 4 PBRNs to disseminate SDM for asthma care. The 4 PBRNs are: (1) MAPPR, the lead group, affiliated with Atrium Health (formerly Carolinas HealthCare System) in Charlotte; (2) North Carolina Network (NCnet) affiliated with the University of North Carolina at Chapel Hill; (3) Primary Care Research Consortium (PCRC) affiliated with Duke University in Durham; and (4) Eastern Carolina Association for Research and Education (ECARE) affiliated with East Carolina University and Vidant Health System in Greenville.

As previously described [37], 30 primary care practices widely distributed across the state of North Carolina were recruited for the ADAPT-NC Study by the 4 PBRNs. Briefly, 476 primary care practices were eligible to participate by having at least 75 patients with a diagnosis of asthma and Medicaid insurance. The PBRNs recruited practices in their geographic regions on a voluntary basis through in-person conversations, email, and/or phone calls. MAPPR and NCnet each recruited 9 practices; PCRC and E-CARE each recruited 6 practices.

\section{Study design}

The objective of the ADAPT-NC Study was to compare 3 dissemination strategies for implementing an asthma SDM toolkit intervention into primary care practices [29]. As previously described, 10 practices were cluster randomized into each of the 3 arms: (1) facilitator-led dissemination involving a 12-week rollout of the toolkit intervention; (2) traditional dissemination involving a one-hour lunch-and-learn presentation of the intervention; and (3) a usual care control group with no active intervention. This manuscript focuses on the 10 practices randomized into the facilitator-led arm of the ADAPT-NC Study (Fig. 2). Baseline practice level data is displayed in Table 1. Overall, the practices' asthma patients were largely pediatric. Number of providers ranged from 2 to 34 with 6 practices part of a healthcare system and 4 private practices.

\section{Practice facilitators}

An experienced lead PF from MAPPR, a physician assistant, trained PFs from each of the 4 participating PBRNs in a train-the-trainer model. MAPPR, NCnet, and ECARE each utilized 1 full-time PF whereas PCRC had 2 part-time PFs. The PFs were all registered nurses with bachelor's degrees and had over 100 years of combined nursing experience. The PBRN PFs all had previous experience in research as well as health coaching and/or practice facilitation with additional certifications including Certified Practice Facilitator (CPF), Certified Clinical Research Professional (CCRP), and Certified in User Experience (UXC).

\section{Training day}

A one-day training event was held for PBRN PFs and additional researchers during which the 12-week rollout

\section{Facilitator-Led Practices Recruited for ADAPT-NC}

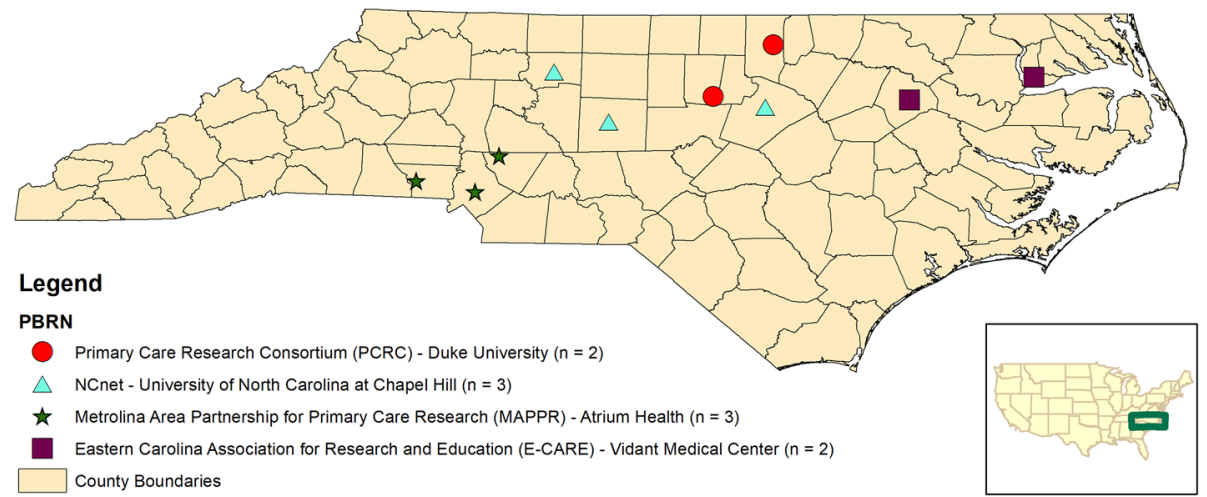

Fig. 2 Geographic Distribution of Facilitator-Led Practices Recruited by Practice-Based Research Network across North Carolina. The map depicted in Fig. 2 is our own 
Table 1 Facilitator-Led Practices Baseline Data

\begin{tabular}{|c|c|c|c|c|c|c|}
\hline PBRN & Site \# & Practice Setting & \# Providers & \# Patients & $\begin{array}{l}\text { \# Asthma Patients } \\
\text { (\% Practice) }\end{array}$ & $\begin{array}{l}\% \text { Pediatric } \\
\text { Asthma Patient }\end{array}$ \\
\hline \multirow[t]{3}{*}{ MAPPR } & 1 & Healthcare System & 2 & 690 & $78(11.3)$ & 55.1 \\
\hline & 2 & Healthcare System & 6 & 4,326 & $401(9.3)$ & 100.0 \\
\hline & 3 & Healthcare System & 9 & 2,909 & $244(8.4)$ & 100.0 \\
\hline \multirow[t]{3}{*}{ NCnet } & 4 & Private Practice & 6 & 1,590 & $120(7.5)$ & 65.8 \\
\hline & 5 & Private Practice & 34 & 2,950 & $375(12.7)$ & 100.0 \\
\hline & 6 & Private Practice & 7 & 2,130 & $205(9.6)$ & 97.1 \\
\hline \multirow[t]{2}{*}{ PCRC } & 7 & Private Practice & 9 & 2,529 & 352 (13.9) & 99.7 \\
\hline & 8 & Healthcare System & 8 & 1,384 & $156(11.3)$ & 77.6 \\
\hline \multirow[t]{2}{*}{ E-CARE } & 9 & Healthcare System & 6 & 1,028 & $122(11.9)$ & 51.6 \\
\hline & 10 & Healthcare System & 3 & 2,121 & $290(13.7)$ & 100.0 \\
\hline \multicolumn{3}{|c|}{ Total Combined } & 90 & 21,657 & $2,343(10.8)$ & 84.7 \\
\hline
\end{tabular}

PBRN Practice-based research network, MAPPR Mecklenburg Area Partnership for Primary Care Research, NCnet North Carolina Network, PCRC Primary Care Research Consortium, E-CARE Eastern Carolina Association for Research and Education

of the asthma SDM toolkit intervention was explained in detail, with emphasis placed on using an adaptable and flexible approach to implementation. A manual of operating procedures was utilized to outline a general framework for the study, highlighting the aim to weave participation at the PBRN and practice level through every aspect of disseminating asthma SDM. Education included an asthma review, inhaler technique and peak flow meter teaching, and toolkit overview.

\section{Practice facilitator remote meetings}

Following the training day, ongoing biweekly PF remote meetings with video conferencing and screen sharing capabilities were facilitated with the PFs who were located throughout the state. These online meetings allowed the PFs to learn the intervention from the lead $\mathrm{PF}$, share best practices and lessons learned with each other, as well as problem solve challenges together. The lead PF presented topics such as additional asthma education, recruitment tips, step-by-step intervention training, and how to promote sustainability of the intervention. The PF remote meetings were recorded so topics could be revisited by the PFs as needed.

\section{Practice facilitator process improvement surveys}

Evaluation of PF engagement was measured through process improvement surveys. One year after the rollouts began and again 6 months later, the PBRN PFs were sent anonymous surveys evaluating team dynamics and communication preferences to elicit improvement suggestions. The feedback was used by the lead PF to iteratively adapt to the needs of the group as the study progressed. Please see Supplementary File 1 for the complete Practice Facilitator Process Improvement Survey.

\section{Facilitator-led dissemination intervention}

Figure 3 depicts how the lead PF interacted with the PFs from the 4 PBRNs, supported by their research teams, at the 10 facilitator-led practices.

PFs from the PBRNs trained their facilitator-led practices in the asthma SDM intervention, adapting it to their practices' cultures, over a 12-week rollout period. The 12-week rollouts consisted of weekly hour-long meetings at the practice's convenience and included key personnel to form a core team typically comprised of a provider champion, practice manager, health coach, nurses, and registration staff [24, 37]. Each week the PF led the core team through a new training topic including: asthma appropriate care and action plans, population management, logistics of scheduling, patient recruitment, and asthma SDM toolkit training, all culminating in the development of asthma SDM visits or clinics at the practice's discretion. The PF assisted the core team in adapting the toolkit from the previous pilot study [39] into a version that suited their practice's specific needs. Time was allotted to allow the core team at the practice to role play the health coaching toolkit process and work through the visits or clinics in a dress rehearsal fashion. Generally, by week 9 of the rollout, the practice was encouraged to see their first asthma patients for SDM. The remaining weeks of the rollout involved debriefing, troubleshooting, and feedback to improve the process in preparation for future SDM visits or clinics (Fig. 4).

After 1 year, the PF revisited their facilitator-led practices and met again with their core teams for "refresher" training sessions, aiming to promote sustainability of the intervention. The refresher sessions were $1 \mathrm{~h}$-long meetings where success was celebrated, barriers were tackled, and next steps such as adding additional providers and/ 


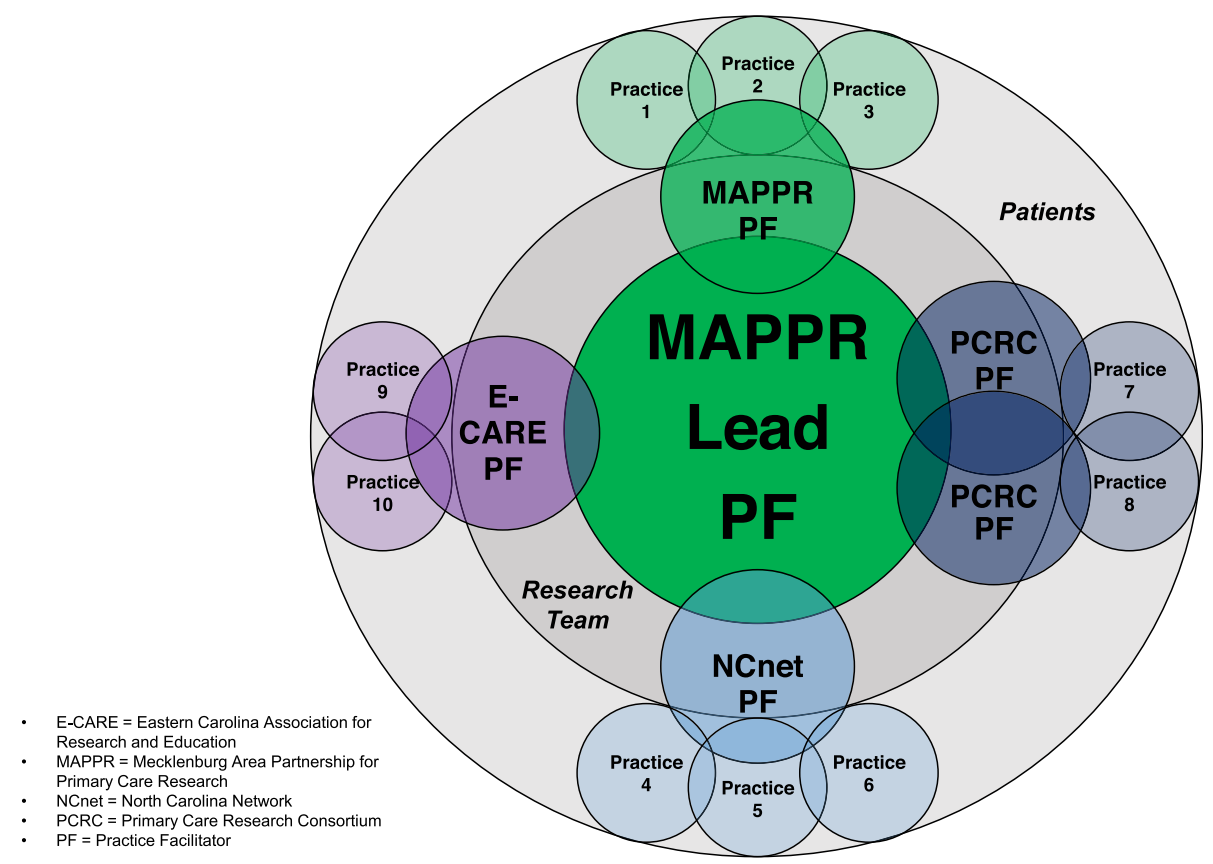

Fig. 3 Facilitator-Led Dissemination Model of Practice Facilitation

or health coaches to the intervention's core team were planned.

Throughout the 3-year project, the PFs were available to their facilitator-led practices for additional training or consultation as requested. Altogether the PFs spent a

\begin{tabular}{|c|l|}
\hline Week & \multicolumn{1}{|c|}{ Training Topic } \\
\hline 1 & $\begin{array}{l}\text { Kick-Off and Introduction to Asthma Shared } \\
\text { Decision Making (SDM) }\end{array}$ \\
\hline 2 & Asthma Appropriate Care and Action Plans \\
\hline 3 & Population Management \\
\hline 4 & Logistics of Scheduling \\
\hline 5 & Patient Recruitment \\
\hline 6 & Asthma SDM Toolkit Training \\
\hline 7 & Health Coach Role Playing \\
\hline 8 & Final Preparation and Dress Rehearsal \\
\hline 9 & First Asthma SDM Clinic or Toolkit Visit \\
\hline 10 & Debriefing from First Asthma SDM Clinic or Visit \\
\hline 11 & Feedback and Troubleshooting \\
\hline 12 & Feedback and Troubleshooting \\
\hline 4
\end{tabular}

Fig. 4 Facilitator-Led Intervention 12-Week Rollout Schedule minimum of $13 \mathrm{~h}$ on site at each practice while hosting the training sessions during the rollouts and refreshers, plus an additional 1-4h per week on average in the 18 months post rollout responding to various questions and concerns depending on the practice's individual needs. Requests included, for example, assistance with additional asthma education for clinical staff or more health coaching practice with the toolkit. Therefore, the total dosage of PF support ranged from approximately 100$400 \mathrm{~h}$ throughout the entire study period.

\section{Facilitator-led monthly calls}

Core team members from the 10 facilitator-led practices were invited to participate in a monthly call with the PFs and PBRN researchers in order to encourage collaboration, share lessons learned, brainstorm, and discuss relevant project updates. Each call centered on a theme to guide the discussion. Core team members from the facilitator-led practices were engaged to suggest call themes which included: patient recruitment, flu shots, SDM documentation, productivity and billing, maintenance of certification and patient centered medical homes, SDM clinic or visit scheduling, new staff training, and medication options to control asthma. The first call took place after all PBRNs had rolled out at their practices. After the 6th call, the calls moved to bimonthly in response to the group's feedback then continued through the end of the study. A total of 15 calls were held altogether. 


\section{Results}

Overall, the asthma SDM intervention was successfully implemented within the 4 PBRNs. All 10 facilitator-led practices remained engaged with their PFs, receiving at least $100 \mathrm{~h}$ of PF support in the 18 months post rollout, with 8 out of the 10 practices able to incorporate and sustain SDM visits or clinics. Of the 2 practices not able to fully implement, 1 practice experienced a $75 \%$ staffing turnover within the first year of the project and chose to focus on day-to-day clinic operations instead of SDM for asthma care. The other practice struggled with provider buy-in secondary to lack of leadership support in prioritizing SDM.

As previously described, the facilitator-led practices reported higher levels of SDM occurring in their asthma visits compared to the traditional lunch-and-learn practices $(75 \%$ vs $66 \%, p=0.001)$ and the facilitator-led practices also had the lowest proportion of patients visiting the ED for exacerbations [29].

\section{Highlights and obstacles}

Table 2 summarizes some of the highlights and obstacles that the PBRN PFs encountered. Each PF had the opportunity to work with a mix of practices, including one or more highly motivated practices that rose to the challenge of incorporating this complex chronic disease intervention into their daily routine.

One practice filmed a video to promote SDM within their community. Another practice that was in a network with 5 locations requested to receive the intervention simultaneously which was achieved through deployment of a live conferencing system with cameras in meeting rooms at each location, allowing the PF to train the multisite group together. A PF struggled with engagement at a practice after the provider champion shifted to working part-time until the solution of working more closely with the practice's staff helped the momentum return.

Common obstacles included provider and staff turnover, lengthy distances for the PFs to travel to some of their practices, challenges finding a common meeting time for core team members and their PF, as well as difficulty reaching busy providers by phone and email.

\section{Practice facilitator process improvement surveys}

Responses from the initial and follow-up PF surveys for process improvement yielded improved PF communication and team dynamics over time (Table 3). Compared with the initial survey, the follow-up survey indicated the PFs overall felt that there was more acknowledging and more contributions of ideas and opinions, as well as less speaking for another person, interrupting, questioning, and disagreeing. Other survey-related improvements included more direct communication, functioning as a team, cooperation, listening, respect, and ideas valued. The PFs indicated in follow-up that they felt the project was more on track with improved use of their time and skills. Midway through the intervention, the biweekly PF remote meetings were changed to monthly in response to the feedback.

Table 2 Practice Facilitation Highlights and Obstacles

\begin{tabular}{|c|c|c|c|}
\hline PBRN & $\begin{array}{l}\text { Site } \\
\#\end{array}$ & Highlights & Obstacles \\
\hline \multirow[t]{3}{*}{ MAPPR } & 1 & $\begin{array}{l}\text { Introduced the concept of SDM; provided basic asthma } \\
\text { education to staff }\end{array}$ & Unable to adopt SDM due to competing priorities \\
\hline & 2 & $\begin{array}{l}\text { Transitioned from group shared medical appointments to } \\
\text { individualized SDM; evolved to become a self-sufficient team }\end{array}$ & Resistant to change at first \\
\hline & 3 & $\begin{array}{l}\text { Eagerly engaged early on; willing to commit to team } \\
\text { approach for SDM care }\end{array}$ & Provider, staff, and administrative turnover \\
\hline \multirow[t]{3}{*}{ NCnet } & 4 & $\begin{array}{l}\text { Completed everything asked and more; developed video } \\
\text { to promote SDM for patients }\end{array}$ & $\begin{array}{l}\text { Not all providers participated; long distance for PF to travel } \\
\text { to practice }\end{array}$ \\
\hline & 5 & $\begin{array}{l}\text { All providers at } 5 \text { locations within group practice engaged; } \\
\text { tech-savvy, modified SDM tools for their website }\end{array}$ & $\begin{array}{l}\text { All } 5 \text { locations wanted to receive the intervention simultaneously; } \\
\text { PF unable to visit all locations }\end{array}$ \\
\hline & 6 & Provided basic asthma education to staff & $\begin{array}{l}\text { Long distance for PF to travel to practice; provider and staff } \\
\text { turnover }\end{array}$ \\
\hline \multirow[t]{2}{*}{ PCRC } & 7 & $\begin{array}{l}\text { PF process built relationships for future research opportunities; } \\
\text { staff excited to take on new roles }\end{array}$ & $\begin{array}{l}\text { Difficult to find suitable meeting time for providers and staff } \\
\text { together; provider champion had competing priorities for time }\end{array}$ \\
\hline & 8 & $\begin{array}{l}\text { Enthusiastic team interested in new roles; staff growth; } \\
\text { became more comfortable with SDM }\end{array}$ & $\begin{array}{l}\text { Difficult to reach staff by phone and email; long distance for PF } \\
\text { to travel to practice }\end{array}$ \\
\hline \multirow[t]{2}{*}{ E-CARE } & 9 & $\begin{array}{l}\text { Introduced different length visits to accommodate more } \\
\text { SDM opportunities }\end{array}$ & $\begin{array}{l}\text { Provider motivation; health coaching was a new concept at the } \\
\text { practice; few referrals initially }\end{array}$ \\
\hline & 10 & Developed reminder system to engage providers & Provider and staff turnover \\
\hline
\end{tabular}


Table 3 Practice Facilitator Process Improvement Survey Results: Response Averages from Initial and Follow-Up Surveys

\begin{tabular}{|c|c|c|c|}
\hline \multicolumn{2}{|c|}{$\begin{array}{l}\text { Question 1: Considering the dynamics of the team, how much do you think that each of } \\
\text { the following behaviors occur when we meet and interact with each other? }\end{array}$} & \multirow{2}{*}{$\begin{array}{l}\text { Initial Survey } \\
\begin{array}{l}n=5 \\
\text { mean (SD) } \\
3.2(0.8)\end{array}\end{array}$} & \multirow{2}{*}{$\begin{array}{l}\text { Follow-Up Survey } \\
\boldsymbol{n}=\mathbf{3} \\
\text { mean (SD) } \\
4.0(0.0)\end{array}$} \\
\hline Positive Attributes & Contributing ideas and opinions & & \\
\hline & Acknowledging & $3.4(0.9)$ & $4.0(0.0)$ \\
\hline & Agreeing & $3.6(0.9)$ & $3.7(0.6)$ \\
\hline & Negotiating & $3.2(1.1)$ & $3.7(0.6)$ \\
\hline & People speaking up for themselves and their opinions & $3.3(0.5)$ & $3.0(1.0)$ \\
\hline & Summarizing & $3.8(0.8)$ & $4.0(1.0)$ \\
\hline \multirow[t]{4}{*}{ Negative Attributes } & Disagreeing & $2.2(0.4)$ & $1.7(0.6)$ \\
\hline & Interrupting & $3.4(0.5)$ & $3.0(0.0)$ \\
\hline & Questioning & $3.2(0.8)$ & $2.3(0.6)$ \\
\hline & Speaking for another person & $2.6(0.9)$ & $1.7(0.6)$ \\
\hline \multicolumn{2}{|c|}{$\begin{array}{l}\text { Question 2: Please select the response that represents the extent to which the following } \\
\text { statements apply to the research team }\end{array}$} & $\begin{array}{l}\text { Initial Survey } \\
n=5 \\
\text { mean (SD) }\end{array}$ & $\begin{array}{l}\text { Follow-Up Survey } \\
n=3 \\
\text { mean (SD) }\end{array}$ \\
\hline \multicolumn{2}{|c|}{ Decisions made are being put into action } & $3.6(0.9)$ & $4.0(1.0)$ \\
\hline \multicolumn{2}{|c|}{ Everyone's ideas were valued } & $3.4(0.9)$ & $4.0(1.0)$ \\
\hline \multicolumn{2}{|c|}{ I got enough information to understand the big picture } & $3.8(0.8)$ & $4.0(1.0)$ \\
\hline \multicolumn{2}{|c|}{ I was motivated to put forth my best efforts } & $3.8(0.8)$ & $4.0(1.0)$ \\
\hline \multicolumn{2}{|l|}{ I was respected } & $3.4(1.5)$ & $4.3(0.6)$ \\
\hline \multicolumn{2}{|c|}{ I was told when I did a good job } & $3.6(1.1)$ & $4.3(1.2)$ \\
\hline \multicolumn{2}{|c|}{ Our decisions stayed on track } & $3.6(0.9)$ & $4.0(0.0)$ \\
\hline \multicolumn{2}{|c|}{ People functioned as a team } & $3.5(0.9)$ & $4.0(0.0)$ \\
\hline \multicolumn{2}{|c|}{ People were cooperative and considerate } & $3.4(0.9)$ & $4.0(0.0)$ \\
\hline \multicolumn{2}{|c|}{ People were direct and honest with each other } & $3.4(0.9)$ & $4.0(0.0)$ \\
\hline \multicolumn{2}{|c|}{ People were good listeners } & $3.0(0.7)$ & $3.7(0.6)$ \\
\hline \multicolumn{2}{|c|}{ The meeting tapped the creative potential of all people present } & $2.8(0.8)$ & $3.7(0.6)$ \\
\hline \multicolumn{2}{|l|}{ Time was well spent } & $2.8(0.8)$ & $3.7(0.6)$ \\
\hline
\end{tabular}

Answer choices: (1) to a very little extent; (2) to a little extent; (3) to some extent; (4) to a great extent; (5) to a very great extent All 5 PFs completed the initial survey and 3 of the 5 PFs completed the follow-up survey

SD Standard Deviation

\section{Discussion}

Practice facilitation utilizing research nurses brought a comprehensive approach to implementation of a SDM toolkit intervention for patients with asthma in the ADAPT-NC Study. Leveraging the train-the-trainer model and elements of community-placed research, this facilitator-led implementation demonstrates effective use of research nurses as PFs to disseminate SDM for asthma care into primary care practices offering the potential for broader dissemination of complex interventions utilizing remote meeting capabilities and research nurses as PFs.

This study adds to the developing knowledge of best practices for implementation of large-scale, complex, primary care interventions through practice facilitation. Baskerville et al. concluded in their systematic review that primary care practices are nearly 3 times more likely to adopt evidence-based guidelines through practice facilitation when there is tailoring of the intervention [7]. Qualitative studies of primary care practice facilitation of complex interventions echo the importance of facilitating team communication, iterative evaluation of the implementation process with real-time feedback, facilitator integration into the practices, and flexibility [43, 44].

To date, there is little evidence directly describing the role of nurses as practice facilitators. However, attributes of nurses most likely associated with success in practice facilitation are well described. These include their empathetic approaches to care, inter- and multidisciplinary team collaboration, as well as training in protocols, evidence-based care, quality improvement, leadership, and communication skills [45-50].

Research nurses demonstrated these skills during intervention rollouts in the ADAPT-NC Study. Not only 
had their training taught them to be empathetic and adaptable problem solvers, they also displayed versatile disease knowledge and understanding, along with effective communication skills. This model of practice facilitation leveraging nurses suggests potential as a method to implement research into practice, which may be further adapted to suit the needs of other populations, diseases or conditions, and settings [51].

Throughout the practice facilitation process in the ADAPT-NC Study, the PFs expressed common lessons learned: to be patient, persistent, pliable, and persevere. The PFs needed to patiently await responses from busy providers caring for patients first. Persistence in the form of frequent reminders was important for the PFs to keep the project running on track, sometimes arriving in person if the situation permitted. The PFs showed pliability when providing their practices with ample options and resources to tailor the intervention to their individual needs. Adapting to the changing needs of the varying practices required perseverance in the form of flexibility and quick thinking. The importance of establishing a trusting relationship with the practice, then building upon it with and frequent communication, was paramount to success.

\section{Limitations}

In line with other real-world, pragmatic implementations, our study had several limitations. First, the 10 facilitatorled practices all agreed voluntarily to participate in the study, introducing a possible source of selection bias.

While most practices were highly motivated to integrate asthma SDM, each PBRN had 1 practice that struggled to meet the demands of this complex project. Frequent staff turnover and lack of provider buy-in proved to be the main limitations of struggling practices. It was challenging for the practices and PFs to continually train newly hired staff with no previous knowledge of the implementation or SDM intervention for asthma care. Staff motivation was impacted when practices lacked strong leadership such as a champion to support the program.

With the small number of PFs involved in this study and in completing process improvement surveys, there was a risk that social desirability and unmasking may have influenced their survey responses.

While we were able to provide process improvement data back to the PFs, due to delays in obtaining disease outcome data we were not able to supply the 10 facilitator-led practices with clinically relevant outcomes results as originally planned.

\section{Conclusions}

This study demonstrated effective use of research nurses as practice facilitators during the dissemination of an asthma SDM intervention into primary care practices across the state of North Carolina, adding to the knowledge of best practices by describing a model of largescale implementation of a complex intervention through practice facilitation with nurses. Future randomized controlled trials using practice facilitation should incorporate cost effectiveness analysis to determine the potential impacts of wider adoption.

\section{Supplementary information}

Supplementary information accompanies this paper at https://doi.org/10. 1186/s12912-020-00414-0.

Additional file 1: Supplementary File 1. Practice Facilitator Process Improvement Survey. Survey used to evaluate practice facilitator engagement, including team dynamics and communication preferences, to elicit improvement suggestions over time.

\section{Abbreviations}

ADAPT-NC: Asthma Dissemination Around Patient-centered Treatments in North Carolina; CCRP: Certified Clinical Research Professional; CPF: Certified Practice Facilitator; E-CARE: Eastern Carolina Association for Research and Education; ED: Emergency Department; MAPPR: Mecklenburg Area

Partnership for Primary Care Research; NC: North Carolina; NCnet: North Carolina Network; PCORI: Patient-Centered Outcomes Research Institute; PBRN: Practice-based research network; PF: Practice facilitator; PCRC: Primary Care Research Consortium; SDM: Shared decision making; UXC: Certified in User Experience

\section{Acknowledgements}

We gratefully acknowledge members of the 4 participating practice-based research networks (PBRN) for their commitment to and support of this project; the 10 primary care practices and their patients for their participation and engagement over the 3 years; Dr. Thomas Ludden, Dr. Kathleen Mottus, Mrs. Madeline Mitchell, and Mrs. Heather Deanes for their assistance with manuscript preparation; Dr. Kristine Schmidt for initial PBRN principal investigation; and Mrs. Beth Patterson, Mrs. Delane Gewirtzman, and Mrs. Debra Nirella for practice facilitation.

\section{Authors' contributions}

LS, the Lead Practice Facilitator, led the writing of this manuscript, with HT, the Principal Investigator, a major contributor. Practice-based research network (PBRN) Practice Facilitators KR, JR, and LH assisted with editing and were content experts for the Highlights and Obstacles section. PBRN investigators JH and RJD critically revised the manuscript; PB made substantial contributions to the concept and design. All authors read and approved the final manuscript prior to submission.

\section{Funding}

This study was funded by the Patient-Centered Outcomes Research Institute (PCORI); Grant \# CD-12-11-4276. The opinions in this publication are solely the responsibility of the authors and do not necessarily represent the views of PCORI, its Board of Governors, or Methodology Committee. PCORI had no role in the design of the study, collection, analysis, interpretation of data, nor manuscript writing.

\section{Availability of data and materials}

All data generated and analyzed during this study are included in this published article.

\section{Ethics approval and consent to participate}

"Comparing Traditional and Participatory Dissemination of a Shared Decision Making Intervention" (ADAPT-NC) received research approval from the Institutional Review Board at Atrium Health (formerly Carolinas HealthCare System) on August 7, 2013 (IRB File \# 08-13-09E). Because this study took place at the practice level, no individual patient consent was required. The Practice Facilitators were not consented for process improvement survey 
collection because this work was considered "quality improvement" by the Atrium Health IRB. IRB Policy for quality improvement studies at Atrium Health is as follows:

"Quality Improvement:

Quality Improvement projects are not covered by IRB requirements. Members of the Atrium workforce are allowed by HIPAA to use protected health information for Quality Improvement projects without patient authorization. (HIPAA Privacy Rule Permitted Uses and Disclosures. Section (2) Treatment, Payment, Health Care Operations)".

\section{Consent for publication}

Not applicable.

\section{Competing interests}

The authors declare that they have no competing interests.

\section{Author details}

${ }^{1}$ Atrium Health, Department of Family Medicine Research, 2001 Vail Avenue, Suite 400B Mercy Medical Plaza, Charlotte, NC 28207, USA. ${ }^{2}$ University of North Carolina at Chapel Hill, 160 N. Medical Drive, CB 7064, Chapel Hill, NC 27599, USA. ${ }^{3}$ Duke University Medical Center, 2608 Erwin Road, Suite 210, Durham, NC 27705, USA. ${ }^{4}$ Department of Family Medicine, University of North Carolina at Chapel Hill, 590 Manning Drive, CB 7595, Chapel Hill, NC 27599-7595, USA. ${ }^{5}$ Division of General Internal Medicine, Department of Medicine, Duke University Medical Center, 200 Morris Street, 3rd Floor, Durham, NC 27701, USA. GVidant Medical Group, 2000 Venture Tower Drive, Greenville, NC 27834, USA.

\section{Received: 29 April 2019 Accepted: 20 March 2020}

Published online: 18 May 2020

\section{References}

1. Dickinson WP, Dickinson LM, Nutting PA, Emsermann CB, Tutt B, Crabtree BF, Fisher L, Harbrecht M, Gottsman A, West DR. Practice facilitation to improve diabetes care in primary care: a report from the EPIC randomized clinical trial. Ann Fam Med. 2014;12(1):8-16.

2. Liddy C, Hogg W, Singh J, Taljaard M, Russell G, Deri Armstrong C, Akbari A, Dahrouge S, Grimshaw JM. A real-world stepped wedge cluster randomized trial of practice facilitation to improve cardiovascular care. Implementation Sci. 2015;10:150

3. Nagykaldi Z, Mold JW, Robinson A, Niebauer L, Ford A. Practice facilitators and practice-based research networks. J Am Board Fam Med. 2006;19(5): 506-10

4. Hogg W, Lemelin J, Moroz I, Soto E, Russell G. Improving prevention in primary care: evaluating the sustainability of outreach facilitation. Can Fam Phys. 2008:54(5):712-20.

5. Kottke TE, Solberg LI, Brekke ML, Conn SA, Maxwell P, Brekke MJ. A controlled trial to integrate smoking cessation advice into primary care practice: doctors helping smokers, round III. J Fam Pract. 1992;34(6):701-8.

6. Dietrich AJ, O'Connor GT, Keller A, Carney PA, Levy D, Whaley FS. Cancer: improving early detection and prevention. A community practice randomised trial. Bmj. 1992;304(6828):687-91.

7. Baskerville NB, Liddy C, Hogg W. Systematic review and meta-analysis of practice facilitation within primary care settings. Ann Fam Med. 2012;10(1): 63-74.

8. Meropol SB, Schiltz NK, Sattar A, Stange KC, Nevar AH, Davey C, Ferretti GA, Howell DE, Strosaker R, Vavrek P, et al. Practice-tailored facilitation to improve pediatric preventive care delivery: a randomized trial. Pediatrics. 2014;133(6):e1664-75.

9. Parchman ML, Noel PH, Culler SD, Lanham HJ, Leykum LK, Romero RL, Palmer RF. A randomized trial of practice facilitation to improve the delivery of chronic illness care in primary care: initial and sustained effects. Implementation Sci. 2013;8:93.

10. Mold JW, Fox C, Wisniewski A, Lipman PD, Krauss MR, Harris DR, Aspy C, Cohen RA, Elward K, Frame $P$, et al. Implementing asthma guidelines using practice facilitation and local learning collaboratives: a randomized controlled trial. Ann Fam Med. 2014;12(3):233-40.

11. Noel PH, Romero RL, Robertson M, Parchman ML. Key activities used by community based primary care practices to improve the quality of diabetes care in response to practice facilitation. Qual Prim Care. 2014;22(4):211-9.
12. Registered Nurse [https://www.nursing.org/careers/registered-nurse/. Accessed: 30 Aug 2018.].

13. Brimmer DJ, McCleary KK, Lupton TA, Faryna KM, Hynes K, Reeves WC. A train-the-trainer education and promotion program: chronic fatigue syndrome--a diagnostic and management challenge. BMC Med Educ. 2008; 8:49.

14. Tobias CR, Downes A, Eddens S, Ruiz J. Building blocks for peer success: lessons learned from a train-the-trainer program. AIDS Patient Care STDs. 2012;26(1):53-9.

15. Corelli RL, Fenlon CM, Kroon LA, Prokhorov AV, Hudmon KS. Evaluation of a train-the-trainer program for tobacco cessation. Am J Pharm Educ. 2007; 71(6):109.

16. Assemi M, Mutha S, Hudmon KS. Evaluation of a train-the-trainer program for cultural competence. Am J Pharm Educ. 2007;71(6):110.

17. Centers for Disease Control and Prevention: Asthma [http://www.cdc.gov/ asthma/. Accessed: 21 June 2018].

18. Centers for Disease Control and Prevention: Most Recent Asthma Data [http://www.cdc.gov/asthma/most_recent_data.htm. Accessed: 21 June 2018].

19. Centers for Disease Control and Prevention: Asthma Facts, CDC's National Asthma Control Program Grantees [http://www.cdc.gov/asthma/pdfs/ asthma_facts_program_grantees.pdf. Accessed: 21 June 2018].

20. McWilliams A, Reeves K, Shade L, Burton E, Tapp H, Courtlandt C, Gunter A, Dulin MF. Patient and family engagement in the Design of a Mobile Health Solution for pediatric asthma: development and feasibility study. JMIR mHealth uHealth. 2018;6(3):e68.

21. Wisnivesky JP, Lorenzo J, Lyn-Cook R, Newman T, Aponte A, Kiefer E, Halm EA. Barriers to adherence to asthma management guidelines among inner-city primary care providers. Ann Allergy Asthma Immunol. 2008;101(3):264-70.

22. National Asthma Education and Prevention Program - Expert Panel Report 3: Guidelines for the Diagnosis and Management of Asthma [https://www. nhlbi.nih.gov/sites/default/files/media/docs/asthgdln_1.pdf. Accessed 21 June 2018].

23. Elward K, Blackburn B, Peterson LE, Greenawald M, Hagen MD. Improving quality of care and guideline adherence for asthma through a group selfassessment module. J Am Board Fam Med. 2014;27(3):391-8.

24. Tapp H, Kuhn L, Alkhazraji T, Steuerwald M, Ludden T, Wilson S, Mowrer L, Mohanan S, Dulin MF. Adapting community based participatory research (CBPR) methods to the implementation of an asthma shared decision making intervention in ambulatory practices. J Asthma. 2014;51(4):380-90.

25. Charles C, Gafni A, Whelan T. Decision-making in the physician-patient encounter: revisiting the shared treatment decision-making model. Soc Sci Med. 1999;49(5):651-61.

26. Wilson SR, Strub P, Buist AS, Knowles SB, Lavori PW, Lapidus J, Vollmer WM, Better Outcomes of Asthma Treatment Study G. Shared treatment decision making improves adherence and outcomes in poorly controlled asthma. Am J Respir Crit Care Med. 2010;181(6):566-77.

27. Tapp H, Shade L, Mahabaleshwarkar R, Taylor YJ, Ludden T, Dulin MF. Results from a pragmatic prospective cohort study: Shared decision making improves outcomes for children with asthma. J Asthma. 2017;54(4):392-402.

28. Liu TL, Taylor YJ, Mahabaleshwarkar R, Blanchette CM, Tapp H, Dulin MF. Shared decision making and time to exacerbation in children with asthma. J Asthma. 2018;55(9):949-955.

29. Ludden T, Shade L, Reeves K, Welch M, Taylor YJ, Mohanan S, McWilliams A, Halladay J, Donahue K, Coyne-Beasley T, Dolor RJ, Bray P, Tapp H. Asthma dissemination around patient-centered treatments in North Carolina (ADAPT-NC): a cluster randomized control trial evaluating dissemination of an evidence-based shared decision-making intervention for asthma management. J Asthma. 2018;25:1-12. [Epub ahead of print].

30. Centers for Disease Control and Prevention: Most Recent Asthma State Data [http://www.cdc.gov/asthma/most_recent_data_states.htm. Accessed: 21 June 2018].

31. Tapp H, Hebert L, Dulin M. Comparative effectiveness of asthma interventions within a practice based research network. BMC Health Serv Res. 2011;11:188.

32. Mowrer JL, Tapp H, Ludden T, Kuhn L, Taylor Y, Courtlandt C, Alkhazraji T, Reeves K, Steuerwald M, Andrew M, et al. Patients' and providers' perceptions of asthma and asthma care: a qualitative study. J Asthma. 2015; 52(9):949-56.

33. Reeves KW, Taylor Y, Tapp H, Ludden T, Shade LE, Burton B, Courtlandt C, Dulin M. Evaluation of a pilot asthma care program for electronic 
communication between school Health and a healthcare System's electronic medical record. Appl Clin Inf. 2016;7(4):969-82.

34. Taylor YJ, Tapp H, Shade LE, Liu TL, Mowrer JL, Dulin MF. Impact of shared decision making on asthma quality of life and asthma control among children. J Asthma. 2018;55(6):675-83.

35. Wagner EH, Austin BT, Davis C, Hindmarsh M, Schaefer J, Bonomi A. Improving chronic illness care: translating evidence into action. Health Aff. 2001:20(6):64-78.

36. Minkler M. Community-based research partnerships: challenges and opportunities. J Urban Health. 2005;82(Suppl 2):ii3-12.

37. Tapp H, McWilliams A, Ludden T, Kuhn L, Taylor Y, Alkhazraji T, Halladay J, Derkowski D, Mohanan S, Dulin M. Comparing traditional and participatory dissemination of a shared decision making intervention (ADAPT-NC): a cluster randomized trial. Implement Sci. 2014;9:158.

38. Tapp H, Derkowski D, Calvert M, Welch M, Spencer S. Patient perspectives on engagement in shared decision-making for asthma care. Fam Pract. 2017:34(3):353-7.

39. Atrium Health: Primary Care Asthma Tools [https://asthma.atriumhealth.org/. Accessed: 13 Dec 2018].

40. Welch M, Ludden T, Mottus K, Bray P, Hendrickson L, Rees J, Halladay J, Tapp H. Patient and provider perspectives on uptake of a shared decision making intervention for asthma in primary care practices. J Asthma. 2018; (In Press) (Accepted April 28, 2018).

41. Shade L, Ludden T, Dolor RJ, Halladay J, Reeves K, Rees J, Hendrickson L, Bray P, Tapp H. Using the Consolidated Framework for Implementation Research (CFIR) to evaluate implementation effectiveness of a facilitated approach to an asthma shared decision making intervention. J Asthma. 2019;23:1-10. [Epub ahead of print].

42. Ludden T, Shade L, Welch M, Halladay J, Donahue KE, Coyne-Beasley T, Bray P, Tapp H. What types of dissemination of information occurred between researchers, providers and clinical staff while implementing an asthma shared decision-making intervention: a directed content analysis. BMJ Open. 2020;8;10(3):e030883.

43. Luig T, Asselin J, Sharma AM, Campbell-Scherer DL. Understanding implementation of complex interventions in primary care teams. J Am Board Fam Med. 2018;31(3):431-44.

44. Liddy CE, Blazhko V, Dingwall M, Singh J, Hogg WE. Primary care quality improvement from a practice facilitator's perspective. BMC Fam Pract. 2014; 15:23.

45. Clements A, Curtis K, Horvat L, Shaban RZ. The effect of a nurse team leader on communication and leadership in major trauma resuscitations. Int Emerg Nurs. 2015;23(1):3-7.

46. O'Neill M, Cowman S. Partners in care: investigating community nurses' understanding of an interdisciplinary team-based approach to primary care. J Clin Nurs. 2008;17(22):3004-11.

47. Pehrson C, Banerjee SC, Manna R, Shen MJ, Hammonds S, Coyle N, Krueger CA, Maloney E, Zaider T, Bylund CL. Responding empathically to patients: development, implementation, and evaluation of a communication skills training module for oncology nurses. Patient Educ Couns. 2016;99(4):610-6.

48. Alexaitis I, Broome B. Implementation of a nurse-driven protocol to prevent catheter-associated urinary tract infections. J Nurs Care Qual. 2014;29(3):24552.

49. Jeffers BR, Astroth KS. The clinical nurse leader: prepared for an era of healthcare reform. Nurs Forum. 2013;48(3):223-9.

50. Fischer EA, Jayana K, Cunningham T, Washington M, Mony P, Bradley J, Moses $\mathrm{S}$. Nurse mentors to advance quality improvement in primary health centers: lessons from a pilot program in northern Karnataka, India. Glob Health Sci Pract. 2015;3(4):660-75.

51. Tabak RG, Khoong EC, Chambers DA, Brownson RC. Bridging research and practice: models for dissemination and implementation research. Am J Prev Med. 2012;43(3):337-50.

\section{Publisher's Note}

Springer Nature remains neutral with regard to jurisdictional claims in published maps and institutional affiliations.

\section{Ready to submit your research? Choose BMC and benefit from:}

- fast, convenient online submission

- thorough peer review by experienced researchers in your field

- rapid publication on acceptance

- support for research data, including large and complex data types

- gold Open Access which fosters wider collaboration and increased citations

- maximum visibility for your research: over $100 \mathrm{M}$ website views per year

At BMC, research is always in progress.

Learn more biomedcentral.com/submissions 